\title{
Comprehensive conceptual framework for futures studies in health
}

\author{
Mohammad Hossien Mehrolhassani ${ }^{1}$, AliAkbar Haghdoost ${ }^{2}$, Reza Dehnavieh $^{3}$, Samira Sadat Pourhosseini*4
}

Received: 5 Mar 2018

Published: 9 Dec 2019

\begin{abstract}
Despite the importance of futures studies, unfortunately, this category, especially in the health sector, is an unfamiliar subject to beneficiary groups. Therefore, promoting futures studies and creating the necessary intellectual contexts are among the main pillars for understanding of any kind of futures studies activity in Iran's health sector.
\end{abstract}

Keywords: Futures studies, Health, Causal layered analysis

Conflicts of Interest: None declared

Funding: None

*This work has been published under CC BY-NC-SA 1.0 license.

Copyright $\odot$ Iran University of Medical Sciences

Cite this article as: Mehrolhassani MH, Haghdoost A, Dehnavieh R, Pourhosseini SS. Comprehensive conceptual framework for futures studies in health. Med J Islam Repub Iran. 2019 (9 Dec);33:131. https://doi.org/10.47176/mjiri.33.131

\section{Introduction}

The science of futures studies was welcomed in an unparalleled way by science and technology policymakers of different countries since the early 1990s (1). Futures studies is a systematic process that helps to analyze the future, identify opportunities and future needs (2), and helps decisionmakers to make better decisions at a lower cost (3). The use of foresight methods has many potential benefits, including the ability to understand and interpret environmental changes, the growth of innovative capabilities, and increasing the ability to learn about organizations and the use of strategic decisions (4). Foresight is a suitable and powerful instrument for development (5), which can have a strong effect on competitiveness, creativity, and quality of life (6).

Futures studies, despite its trans disciplinary approach, has the features that place it among the social sciences. Science of futures studies is the knowledge necessary to create intelligent and effective social action through providential thinking (7), and it is $\mathrm{r}$ elated to all society's intellectual

\footnotetext{
Corresponding author: Samira Sadat Pourhosseini,sam_poorhoseyni@yahoo.com

1. Medical Informatics Research Centre, Institute for Futures Studies in Health, Kerman University of Medical Sciences, Kerman, Iran

2. Modeling in Health Research Center, Institute for Futures Studies in Health, Kerman University of Medical Sciences, Kerman, Iran

3. Social Determinants of Health Research Center, Institute for Futures Studies in Health, Kerman University of Medical Sciences, Kerman, Iran

4. Health Services Management Research Center, Institute for Futures Studies in Health, Kerman University of Medical Sciences, Kerman, Iran
}

behavior areas (8). Despite the importance of futures studies, unfortunately, this category, especially in the health sector, is an unfamiliar subject to beneficiary groups. Therefore, promoting futures studies and creating the necessary intellectual contexts is among the main pillars for the realization of any kind of futures studies activity in the health sector of the country (9).

Understanding the concept of this subject and its related generalizations is essential to create a common language, adopt approaches, and learn how to apply different methods of futures studies. Therefore, in this study, a comprehensive conceptual model of futures studies was presented by the authors based on library studies and the authors' experience, which included the subject of futures studies science, its nature and purpose, and the most important related concepts. Then, the framework of the conceptual model was presented with the causal layered analysis and was ultimately adopted based on the key topics for futures studies in health.

$\uparrow$ What is "already known" in this topic:

Despite the importance of futures studies in the health sector, unfortunately, health policymakers still are not familiar with this concept.

$\rightarrow$ What this article adds:

A comprehensive conceptual model of futures studies has been introduced in this study, presenting the subject of futures studies, its nature and purpose, and the most important related concepts. 


\section{Conceptual model}

The model presented in this study is a conceptual model with exploratory, normative, and critical approaches. In this conceptual framework, it was tried to comprehensively integrate different approaches to futures studies as a theoretical model, based on which the position of different approaches to future studies was placed. The key components of the comprehensive model include the subject of futures studies, governance, and systems as the leverage of the distribution of the power of the external factors in guiding the society towards the future. The internal factors of the society, such as doctrine, philosophy and logic, paradigms, and ruling discourses, are another category of key factors that are compared with the model of steepv and CLA in this paper.

Futures studies have social, economic, political, and cultural dimensions. Each society has a history and is moving towards the future. When the history of a society is identified, then, it is possible to draw the probable future from its past trends and events. This is called an explorative approach in futures studies and is the basis for predictions in empirical science and is known as futurism; in this approach, statistics and mathematics are used in the form of quantitative methods such as time series (10). The concept of community observation and environmental scanning is a key concept that provides foresight while analyzing the present and past situation of a society.

On the other hand, the development and progress of any society is considered as duties of sovereignty (11). Therefore, the sovereignty of the society is the guarantor and determiner of the future path of the society, and this is done through the systematization and division of work in various social sectors. Sovereignty executes the power and governs based on a logic and philosophy accepted by the society and it is influenced by the cultural rules and system (value, intellectual and behavioral) of the society. Thus, the more the conformity between the sovereignty and the cultural system of the society, the greater the legitimacy of the sovereignty.

In the model presented in this study, the purpose and meaning of rationality and philosophy is a logic and belief accepted by the individual or society (12). This logic (thought, politics, and philosophy system) is called doctrine, which is the basis of the science of sovereignty (13). Different discourse and paradigms lead to the formation of various philosophies and rationalities. Discourse is in the field of social and cultural knowledge and presents a system of insights, assumptions, statements, and ideas that affect mentalities (14).

Preferable future based on current discourses in the society or the sovereignty doctrine forms the inner layers of the society. This approach of futures studies, which is mainly defined based on rationality, intuition, and internal expectations of the society and sovereignty, is called normative approach and is mainly based on qualitative methods (15). Theorizing has a key role in orienting the society towards desirable futures. Figure 1 represents a conceptual model of futures studies.

The realization of a desirable and preferable future as the purpose of futures studies is of paramount importance, and for this purpose, recognizing the relationships between the

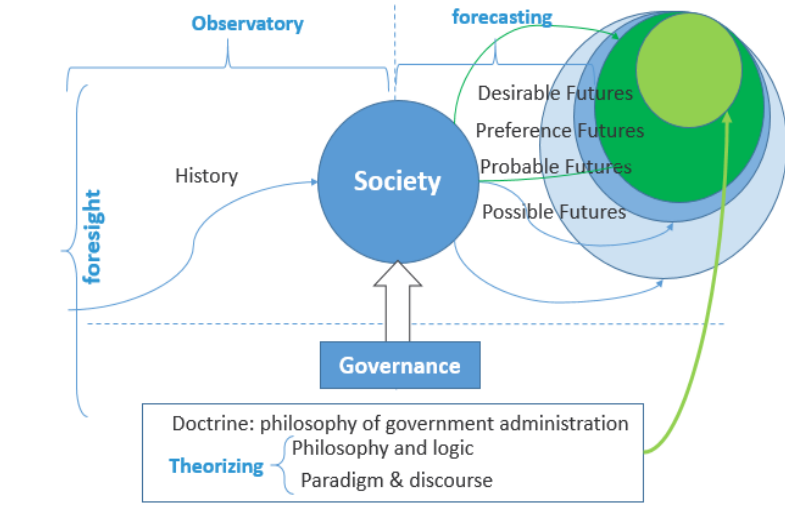

Fig. 1. Futures studies conceptual model

various layers of the society (the intangible inner and tangible outer) and creating a new order based on the doctrine is essential. Thus, in recent years, a critical approach has often been used that is based on critical knowledge in the social sciences that combines, in a particular way, an explorative and normative approaches to change the power balance in the society.

A critical approach of futures studies was established by Sardar and advanced by Enayat Allah with the presentation of the causal layered analysis (CLA) framework, which considers various layers of the society including litany, social causes, discourse, and myth/metaphor for futures studies interventions (16). The adaptation of the proposed model with causal layered analysis (CLA) is presented in Figure 2. The position of the society at the tangible level (litany layer) and the position of governing structures that play the role of system building are placed in the structural layer. The doctrine and philosophy governing the society and the discourse paradigms of governance are also matched with the discourse layers of the society.

It is necessary to use a proportional combination of different methods to conduct a futures studies project in the comprehensive model of futures studies by considering the nature of the desirable problem and the adopted approach. However, more attention should be paid to solve problems. Unfortunately, some studies are very superficial and pay no attention to the ruler doctrine and philosophy, and sometimes the adopted approaches and futures studies methods are used inappropriately, and many of the presuppositions of these methods are not realized in practice. Various methods have been proposed based on the presented model and different approaches of futures studies that have been located in Popper's diamond based on 4 criteria of evidence, expertise, interaction, and creativity (17). Figure 3 shows the locations of methods based on the futures studies criteria and approaches.

Close methods to creativity pole are qualitative methods that are equivalent to the normative approach. The pole of creativity is equivalent to theory, especially discourses and paradigms in the futures studies model; and compared to the CLA model, it is placed in the discourse and myth layer. The methods close to the evidence pole are mostly qualitative, which are equivalent to explorative approaches in future studies. The pole of evidence is equivalent to the 


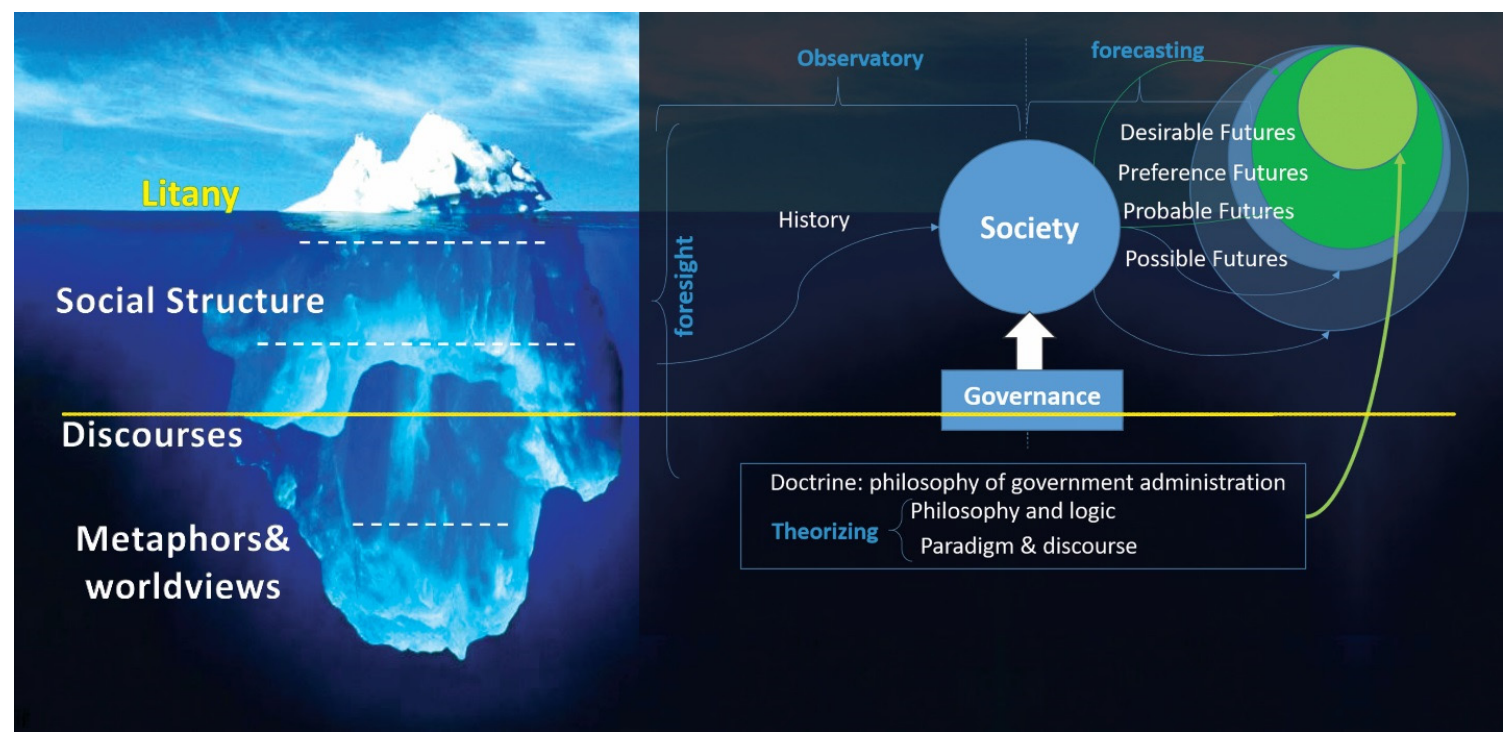

Fig. 2. Model matching with causal layered analysis (CLA)

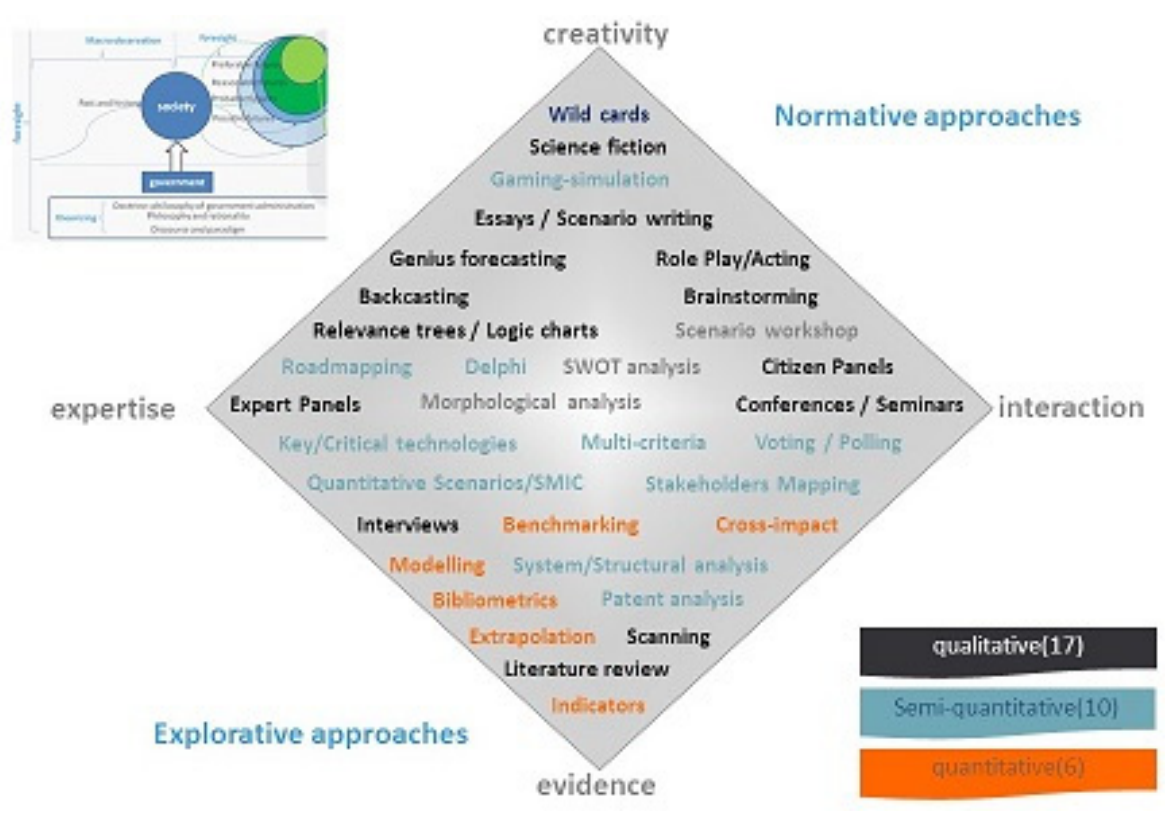

Fig. 3. Widely used methods of futures studies based on futures studies approaches and criteria (17)

community in the model of futures studies and is placed in the litany layer. The methods that are in the pole of interaction and expertise are equivalent to a critical approach. In fact, these 2 poles are the middle layers in the CLA that create structures and establish the relationship between doctrine and evidence.

\section{Conclusion}

Based on the presented model, which has a comprehensive look at all approaches, how they interact, and the application of futures studies frameworks and methods, the following prioritized requirements should be considered for conducting futures studies on the health of any country as a macro sovereignty project:

- Identifying paradigms and health discourses

- Examining mental flows of health philosophy
- Determining the health doctrine appropriate to the governmental structure

- Providing a progress pattern of society health and health sector

- General policies of health system and sector

- Health perspective

- Perspective requirements (Back casting) and determining the roadmap for health

- Determining the executive policies governing the development plans (strategic plan) of the health system

\section{Conflict of Interests}

The authors declare that they have no competing interests.

\section{References}

1. FOREN, A Practical Guide to Regional Foresight, December 2001. 
2. Havas A, Schartinger D, weber M. The impact of foresight on innovation policy-making: recent experiences and future perspectives. Res Eval. 2010;19(2):91-104.

3. Haegeman K, Spiesberger M, Konnola T. Evaluating foresight in transnational research programming. Technol Forecast Soc Change. 2017; 115:313-326.

4. Kononiuk A, Glinska E. Foresight in small enterprise. A case study. Procedia Soc Behav Sci. 2015;213:971-976.

5. Mahmud J. City foresight and development planning case study: Implementation of scenario planning in formulation of the Bulungan development plan. Futures. 2011;43(7): 697-706.

6. Calof J, Richards G, Smith J. Foresight, competitive intelligence and business analytics tools for making industrial programmes more efficient. Foresight-Russia. 2015;9(1):68-81.

7. Bell, W. Foundations of Futures Studies: History, Purposes, and Knowledge, Transaction Pub. 2003.

8. Hosseini Golkar M, Ghazinoory SS, Saghafi F, Eivazi MR, Poursheikhali A, Dehnavieh R. Appropriate types of futures studies scenarios in health. Med J Islam Repub Iran. 2017;31:82.

9. Haghdoost AA, Dehnavieh R, Rashidi M, Mehrolhasani MH, Noorihekmat S. Prospective policy in the health sector in Iran; The status and a framework for future, $2^{\text {nd }}$ national futures studies conference, 2013.

10. Twiss F. Forecasting for Technologist and Engineers: A Practical Guide for Better Dictions, London: Peregrines. 1992.

11. Haghdoost AA, Pourhosseini SS, Emami M, Dehnavieh R, Barfeh T, Mehrolhassani M.M. Foresight in health sciences using CLA method. Med J Islam Repub Iran. 2017.

12. Webster N. The American Spelling Book: Containing the Rudiments of the English Language, for the Use of Schools in the United States. Sterotyped by the publisher, 2018.

13. Delavari R, Dictionary of Political Science and International Relations, Tehran, Delavari, 1999.

14. Inayatullah S. Questioning the Future: Methods and Tools for Organizational and Societal Transformation. Published by Tamkang University Press, Third edition, 2007.

15. Pourmohammadi MR, Hosseinzadeh Daliri K, Ghorbani R, Zali N. Re-engineering of planning process with emphasis on foresight approach. Geogr Dev. 2011;8(20):37-58.

16. Inayatullah $\mathrm{S}$. Theory and practice in transformation: The disowned futures of Integral extension. Futures. 2010;42(2):103-109.

17. Popper R. How are foresight methods selected? Foresight. 2008;10(6):62-89. 